zine successfully reduced the incidence of dysphoric reactions it might also antagonise the antiemetic effect of nabilone. The incidences of other side effects were similar in both treatment arms; sedation and dryness of the mouth occurred most commonly and generally were not too troublesome. Indeed, we suspect that with moderately emetogenic cytotoxic regimens ${ }^{5}$ the occurrence of these side effects could be reduced by using a lower dose of nabilone ( $1 \mathrm{mg}$ twice daily) without necessarily compromising the control of emesis.

Nabilone and prochlorperazine are a good oral antiemetic combination suitable for use with outpatient chemotherapy, but because they are associated with a small incidence of adverse effects on the central nervous system the first course of treatment should be given under inpatient supervision.

We thank Eli Lilly for financial support and Miss A Penrice, our secretary.

1 Cunningham $\mathrm{D}$, Hutcheon $\mathrm{A}$, Soukop $M$, et al. A randomised trial comparing the control of nausea and vomiting induced by cytotoxic drugs. $\mathrm{Br}$ Med $\mathcal{f}$ the control of naus

2 Wada JK, Bogdon DI, Gunnell JC, Hum GJ, Gota CH, Rieth TE. Double-blind, randomized, crossover trial of nabilone vs placebo in cancer chemotherapy. Cancer Treat Rev $1982 ; 9: 39-44$

3 Garb S, Beers AL, Bograd M, et al. Two-pronged study of tetrahydrocannabinol (THC) prevention of vomiting from cancer chemotherapy. International Research Communications System Medical Science 1980;8:203-4.

4 Artim R, DiBella N. Tetrahydrocannabinol (THC) plus prochlorperazine (TCZ) for refractory nausea and vomiting (N/V). Proceedings of the nineteenth annual meeting of the American Society of Clinical Oncology, San Diego, 1983. Baltimore:

5 Sallan SE, Cronin C, Zelen M, Zinberg NE. Antiemetics in patients receiving chemotherapy for cancer. A randomized comparison of delta-9-tetrahydro-

Accepted 4 fuly 1985)

Department of Medical Oncology, Royal Infirmary, Glasgow G4 OSF DAVID CUNNINGHAM, MB, MRCP, Cancer Research Campaign research fellow

GORDON J FORREST, MB, senior house officer

MICHAEL SOUKOP, MB, MRCP, consultant physician

NIGEL L GILCHRIST, FRACP, senior registrar

IAN T CALDER, MSC, MPS, staff pharmacist

University Department of Surgery, Glasgow Royal Infirmary

COLIN S MCARDLE, MD, FRCS, consultant surgeon

Correspondence to: Dr Cunningham.

\section{Gastrointestinal haemorrhage complicating Wegener's granulomatosis}

Wegener's granulomatosis is a vasculitic disorder with distinct clinical and histological features, showing considerable overlap with other diseases within the range of systemic vasculitis. ${ }^{1}$ Classically, pulmonary disease and nasopharyngeal symptoms are universal, with a severe necrotising glomerulonephritis occurring in $80 \%$ of patients and other systems being affected less commonly. ${ }^{2}$ We report on a patient with clinical Wegener's granulomatosis who developed severe gastrointestinal and intraperitoneal haemorrhage. Such a complication has not been reported previously.

\section{Case report}

A 46 year old man presented to the ear, nose, and throat department with a persistent nasal discharge and necrotic ulcers on his buccal mucosa and tongue; biopsy specimens of these were not obtained. He had a six month history of general malaise and weight loss and recent symptoms of polyarthralgia, iritis, and a vasculitic rash on his legs; he had received ibuprofen for two weeks before admission. A chest $x$ ray film showed a cavitating lesion in the right upper lobe, and laboratory investigation showed a normochromic normocytic anaemia with renal failure: haemoglobin concentration was 79 $\mathrm{g} / 1$; erythrocyte sedimentation rate $116 \mathrm{~mm}$ in the first hour; urea concentration $35.7 \mathrm{mmol} / 1(214 \mathrm{mg} / 100 \mathrm{ml})$; and creatinine concentration $540 \mu \mathrm{mol} / 1$ $(6.1 \mathrm{mg} / 100 \mathrm{ml})$. Treatment with cyclophosphamide and hydrocortisone greatly improved his arthralgia, vasculitic rash, and general condition, but his renal function continued to deteriorate and he required haemodialysis. Renal biopsy showed diffuse necrotising crescentic glomerulonephritis with focal segmental granular deposits of $\mathrm{IgG}, \mathrm{IgM}, \mathrm{C} 3$, and C4. Further immunosuppression with pulsed doses of $1 \mathrm{~g}$ methylprednisolone and oral prednisolone ( $60 \mathrm{mg}$ daily) resulted in improved renal function.
Twelve days after admission, when his clinical condition had improved and his erythrocyte sedimentation rate was $27 \mathrm{~mm}$ in the first hour, he suffered a massive gastrointestinal haemorrhage. Mesenteric angiography showed a bleeding point in the distal small bowel. At laparotomy several inflammatory areas were recognisable on the serosal surface of the distal ileum. One metre of distal ileum was resected, which contained nine punched out mucosal ulcers corresponding to the areas of serosal inflammation. The most distal of these bore adherent thrombus.

Histological examination showed active arteritis with fibrinoid necrosis and sparse perivascular lymphocytic infiltration. Postoperatively he suffered an intraperitoneal haemorrhage, the source of which could not be located at re-exploration six hours later. Splenectomy was performed because of a persistent oozing around the spleen, which was grossly abnormal and wrapped in omentum. A small tear was found at the upper pole of the spleen, and histological examination showed multiple infarcts up to $1 \mathrm{~cm}$ diameter with patchy vasculitis and thrombosis of medium sized arteries. Further haemorrhage was controlled by packing the splenic bed. During these procedures 30 units of blood were transfused. He made a good postoperative recovery with impaired but stable renal function (figure).

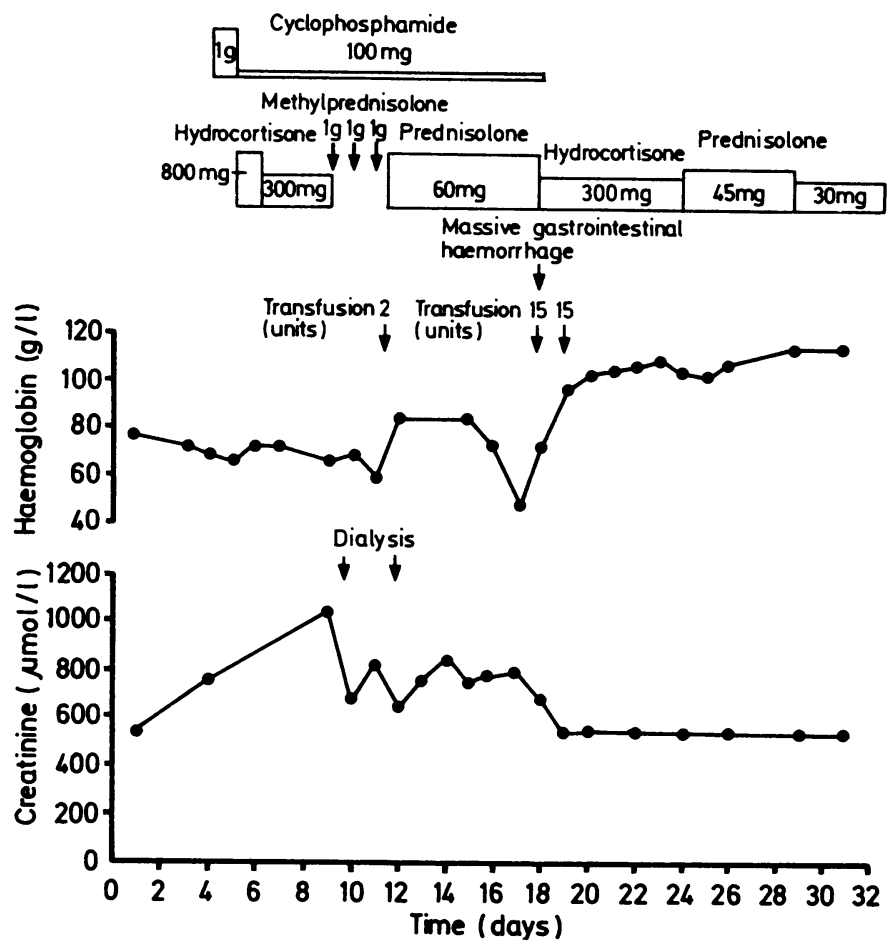

Effect of treatment on serum creatinine concentration, and relation of gastrointestinal haemorrhage to recovery of renal function.

Conversion: SI to traditional units-Creatinine: $1 \mu \mathrm{mol} / 1 \approx 11.3 \mu \mathrm{g} / 100$ ml.

\section{Comment}

Over half of the patients with classical polyarteritis nodosa experience abdominal pain, and $44 \%$ of these have gastrointestinal haemorrhage. ${ }^{3}$ Gastrointestinal complications are rare in Wegener's granulomatosis, being found in four of 36 patients studied by Camilleri et $a l,{ }^{3}$ only one of whom had poorly documented gastrointestinal haemorrhage. Pinching et al reported bleeding from a duodenal ulcer in a patient with Wegener's granulomatosis, although they believed this to be related to steroid treatment as it occurred when the disease was quiescent. ${ }^{4}$ This assumption may be false as bleeding occurred in our patient when clinical and laboratory evidence indicated a response to immunosuppression while histological examination of the gut and spleen showed active arteritis with intravascular thrombus. Our case parallels a report of cortical blindness, presumably thrombotic, occurring in a patient with Wegener's granulomatosis at a time when renal function was improving. ${ }^{5}$ Such observations suggest that different mechanisms have a role in the early systemic manifestations of the disease, which may respond rapidly to immunosuppression, and in the later thrombotic complications secondary to endothelial damage, in which antiplatelet agents and prostacyclin analogues might be of benefit.

We would like to thank Dr D A Jones, consultant physician, Grimsby District General Hospital, for referring the patient. 
1 Fauci AS, Haynes BF, Katz P. The spectrum of vasculitis, clinical, pathological, immunological and therapeutic considerations. Ann Intern Med 1978;89: 660-76.

2 Wolff M, Fauci AS, Horn RG, Dale DC. Wegener's granulomatosis. Ann Intern

3 Camilleri M, Pusey CD, Chadwick VS, Rees AJ. Gastrointestinal manifestations of systemic vasculitis. $Q \mathcal{F}$ Med 1983;206:141-9.

4 Pinching AJ, Lockwood CM, Passell BA, et al. Wegener's granulomatosis: observations on 18 patients with severe renal disease. $Q \Im$ Med 1983;208:435-60. granulomatosis. $\mathrm{Br} f$ Med $1985 ; 290: 676$.

Accepted 4'fuly 1985)

Department of Nephrology and Transplantation, Royal Hallamshire

Hospital, Sheffield S10 2JF

R A COWARD, BM, MRCP, senior registrar

C P GIBBONS, DPHIL, FRCS, clinical research fellow

C B BROWN, MB, FRCP, consultant physician

A T RAFTERY, MD, FRCS, consultant surgeon

Department of Histopathology, Royal Hallamshire Hospital

$M$ A PARSONS, MB, MRCPATH, senior lecturer

J R SHORTLAND, MB, MRCPATH, senior lecturer

Correspondence to: Dr Coward, Department of Medicine, Royal Hallamshire Hospital.

\section{Effect of treatment on symptoms and quality of life in patients with ulcerative colitis: comparative trial of hydrocortisone acetate foam and prednisolone 21-phosphate enemas}

The disability associated with ulcerative colitis and proctitis is considerable and includes decreased working capacity, early rising, increased bowel frequency, fear of incontinence, urgency, and tiredness. ${ }^{1}$ Sexual relationships may be adversely affected. Treatment itself may impose further restrictions on patients with this disease. We have compared the effects of foam and liquid topical corticosteroid preparations on the symptoms and quality of life of patients with distal ulcerative colitis.

\section{Patients, methods, and results}

We studied 46 patients ( 18 men, 28 women) aged 20-64 years with symptomatic relapse of chronic ulcerative colitis. All had histological confirmation of the diagnosis and sigmoidoscopic evidence of current exacerbation. Daily bowel frequency and severity of symptoms were assessed, urgency and lassitude being measured on visual analogue scales. Similar scales were used to assess disturbance of the quality of life caused by the treatment and by the disease, and patients also maintained daily symptom score cards. Treatmen with prednisolone 21-phosphate enemas (Predsol; $20 \mathrm{mg}$ prednisolone 21-phosphate in a buffered solution of $100 \mathrm{ml}$ ) or hydrocortisone acetate foam (Colifoam; $130 \mathrm{mg}$ hydrocortisone acetate in $5 \mathrm{ml}$ foam) was allocated blindly using a prearranged code. It was applied morning and evening for the first two weeks, then nightly for the next fortnight if responses were satisfactory. If responses were unsatisfactory the alternative treatment was supplied. Sigmoidoscopy was repeated after four weeks or if treatment was changed. Data were analysed non-parametrically using the Mann-Whitney U test (two tailed).

Five patients were excluded from analysis. In the enema group two showed poor compliance and one took medication for one week only, and in the foam group one patient was given the wrong medication and another was symptom free at entry. The groups did not differ materially in sex or age distribution, duration of disease or of recent episode, extent of disease, or numbers receiving concomitant sulphasalazine.

Treatments were equally effective in reducing bowel frequency, urgency, incontinence, and lassitude, but tenesmus was more completely alleviated at two weeks in those receiving the prednisolone enemas $(p<0.025)$. Sigmoidoscopic abnormalities improved similarly in both groups. After two weeks of treatment four patients changed from the foam to the enema because of poor response; two had slight symptomatic improvement and two did not. The one patient who changed from liquid treatment to foam did not benefit. No serious adverse reactions were reported.

Considerable disturbance of general activities due to the exacerbation of ulcerative colitis was recorded before treatment started. This decreased during treatment in both groups and was significantly reduced from baseline after four weeks. In all seven variables assessed, however, foam was associated with less interference with general activities than enema treatment, differences being significant for four of the daily activities examined (table). In addition, based on both the physicians' assessments and the patients; diary cards, significant differences favouring the foam were found for the criterion "difficulty of retention" $(p<0.05)$.

\section{Comment}

Other studies have shown that both prednisolone sodium phosphate enemas and hydrocortisone acetate foam are effective, ${ }^{2-5}$ but these have not been directly compared either for clinical value or for patient preference. In this trial the therapeutic efficacy of the two preparations differed little. By contrast, there was a clear difference between treatments in the degree to which they disturbed the quality of life.

Mean (range) analogue scale scores for disturbance of quality of life by treatment. (Scale rated from 0 (no disturbance) to 100 (maximum disturbance possible))

\begin{tabular}{|c|c|c|c|}
\hline \multirow[b]{2}{*}{ Component assessed } & \multirow[b]{2}{*}{ Treatment } & \multicolumn{2}{|c|}{ Duration of treatment } \\
\hline & & 2 weeks & 4 weeks \\
\hline Work or social activities & $\left\{\begin{array}{l}\text { Prednisolone } \\
\text { Hydrocortisone }\end{array}\right.$ & $\begin{array}{c}23(0-99) * \\
4(0-29)\end{array}$ & $\begin{array}{r}11(0-60) \\
6(0-30)\end{array}$ \\
\hline Routine indoor activities & $\left\{\begin{array}{l}\text { Prednisolone } \\
\text { Hydrocortisone }\end{array}\right.$ & $\begin{array}{r}15(0-80) \\
4(0-30)\end{array}$ & $\begin{array}{r}14(0-63) \\
3(0-10)\end{array}$ \\
\hline Routine outdoor activities & $\left\{\begin{array}{l}\text { Prednisolone } \\
\text { Hydrocortisone }\end{array}\right.$ & $\begin{array}{r}17(0-81) \\
7(0-40)\end{array}$ & $\begin{array}{r}15(0-70) \\
3(0-10)\end{array}$ \\
\hline Early rising & $\left\{\begin{array}{l}\text { Prednisolone } \\
\text { Hydrocortisone }\end{array}\right.$ & $\begin{array}{c}23(0-100) \\
4(0-33)\end{array}$ & $\begin{array}{l}8(0-70) \\
2(0-10)\end{array}$ \\
\hline Sexual relationships & $\left\{\begin{array}{l}\text { Prednisolone } \\
\text { Hydrocortisone }\end{array}\right.$ & $\begin{array}{c}18(0-60)^{* *} \\
1(0-3)\end{array}$ & $\begin{array}{r}15(0-89) \\
2(0-10)\end{array}$ \\
\hline Occupational activities & $\left\{\begin{array}{l}\text { Prednisolone } \\
\text { Hydrocortisone }\end{array}\right.$ & $\begin{array}{l}12(0-40)^{*} \\
2(0-14)\end{array}$ & $\begin{array}{l}4(0-15) \\
3(0-20)\end{array}$ \\
\hline Hobbies and recreation & $\left\{\begin{array}{l}\text { Prednisolone } \\
\text { Hydrocortisone }\end{array}\right.$ & $\begin{array}{r}12(0-50) \\
3(0-20)\end{array}$ & $\begin{array}{r}13(0-71) \\
3(0-20)\end{array}$ \\
\hline
\end{tabular}

Mann-Whitney U test (two tailed): *p $<0.05 ;{ }^{* *} \mathrm{p}<0.01$

This was particularly evident at two weeks, when the treatments were used twice daily, and was not attributable to variations in initial severity of the disease. Patients also preferred the foam to the liquid enemas because it was easier to retain.

Modern medicine tends to concentrate on disease, with less consideration for the effect which the disease or its treatment may have on the enjoyment of life. Our results suggest that, in distal ulcerative colitis, treatments which are equally effective clinically may nevertheless differ appreciably in the ways in which they influence the social, family, and professional life of the sufferers.

1 Mallet SJ, Lennard-Jones JE, Bingley J, Gilan E. Living with disease: colitis. Lancet 1978;ii:619-21.

Gaucher P, Champigneulle B. Local treatment of proctocolitis. Comparison between a betamethasone phosphate enema and a rectal foam containing hydrocortisone acetate. Revue Française de Gastroenterologie 1983;193:35-9.

21-phosphate retention enemata in proctocolit of ulcerative colitis. Dis Colon Rectum 1973;16:149-51.

5 Ruddell WSJ, Dickinson RJ, Dixon MF, Axon AIR. Treatment of distal ulcerative colitis (proctosigmoiditis) in relapse: comparison of hydrocortisone enemas and rectal hydrocortisone foam. Gut 1980;21:885-9.

(Accepted 24 fune 1985)

Department of Therapeutics, University Hospital, Nottingham

$\mathrm{K} W$ SOMERVILLE, MB, FRACP, lecturer

M J S LANGMAN, MD, FRCP, professor

Department of Gastroenterology, West Middlesex University Hospital, London

S P KANE, MB, MRCP, consultant physician

Department of Gastroenterology, Western Infirmary, Glasgow

A J MACGILCHRIST, MB, MRCP, registrar

G WATKINSON, MD, FRCP, consultant physician

Department of Gastroenterology, University College Hospital, London

P SALMON, MB, FRCP, consultant physician

Correspondence to: $\mathrm{Dr} \mathrm{K} W$ Somerville, Department of Therapeutics, Floor C, South Block, University Hospital, Nottingham NG7 2UH. 